\title{
NUEVOS DATOS PARA LA BIOGRAFÍA DEL ESCULTOR PEDRO DE MENA
}

\author{
Juan Jesús López-Guadalupe Muñoz
}

La biografía de Pedro de Mena está jalonada de éxitos profesionales que le reportaron prestigio y posición. El conocimiento de su trayectoria vital se incrementa ahora con cierta correspondencia que revela cómo el escultor servía de agente comercial en Málaga para el cabildo de la Catedral de Granada. Por la fecha de esas cartas (1675-1677), deben ponerse en relación con la ejecución de las estatuas orantes de los Reyes Católicos para la capilla mayor de esa Catedral.

En una reciente biografía sobre el escultor bastetano José de Mora (16421724)' nos lamentábamos de la escasez de documentos acerca del genial artista, sin conocerse incluso un solo contrato de obra, lo que extraña aún más si cabe al considerar la notable fama adquirida en vida y la proyección que su nombramiento como Escultor del Rey en 1672 le pudo proporcionar. Caso bien distinto constituye su condiscípulo en el magisterio canesco, el granadino Pedro de Mena y Medrano (1628-1688), del que abundantes documentos ayudan a perfilar con gran riqueza de matices los rasgos, tanto principales como secundarios de su biografía ${ }^{2}$.

En esta línea, como ya hemos apuntado, se presenta aquí cierta correspondencia con canónigos de la Catedral de Granada, mantenida por el escultor desde Málaga, en la que residía desde 1658 como es bien sabido, fortuito hallazgo fruto de las rebuscas en el archivo de la misma Catedral ${ }^{3}$. Estas misivas, fechadas entre 1675 y 1676, están dirigidas al Deán o al Mayordomo de Fábrica de la Catedral de Granada y en ellas se da cuenta del envío de cera adquirida por Mena en el puerto de Málaga con destino a la Catedral granadina, a lo que se unen los asientos y recibos correspondientes a su abono al escultor (documentos 1-3). En una última carta, dirigida al escultor a Granada por su proveedor malagueño, además de informarle del envío de un porte de cera, se le ruega la adquisición de varias piezas de tafetán (documento 4). Esta correspondencia nos introduce en dos aspectos de no poco

${ }^{1}$ LÓPEZ-GUADALUPE MUÑOZ, J.: José de Mora. Granada, Editorial Comares (Colección Biografías Granadinas, $\left.n^{\circ} 12\right), 2000$.

${ }^{2}$ La primera sistematización de la misma es la clásica de ORUETA Y DUARTE, R.de: La vida y la obra de Pedro de Mena y Medrano. Madrid, Centro de Estudios Históricos, 1914. Una puesta al día de la documentación exhumada sobre el escultor en el apéndice documental que incluye la obra Pedro de Mena. III Centenario de su muerte. 1688-1988. Málaga, 1989, págs. 287-305.

3. Archivo de la Catedral de Granada, Fábrica, legajo 166.

4 ORUETA Y DUARTE, R. de: op. cit., pág. 100. 
interés en la trayectoria vital, y también artística, de Pedro de Mena: su participación frecuente en operaciones comerciales y su estrecha relación con el cabildo de la Catedral de Granada.

En cuanto a la primera, un generoso corpus documental delata en nuestro artista un acusado espíritu mercantil y una acomodada posición económica, al parecer mermada al final de sus días ${ }^{4}$. Además de los contratos de su oficio, menudean las ventas de esclavos, arrendamiento y compraventa de casas e incluso comercio de sedas, intensificándose quizás estas operaciones en la década de 1670. En esta época tiene lugar el definitivo encumbramiento económico y social de Mena, en la cima de su prestigio al servir encargos de la Corte, Granada o Córdoba, además de Málaga, y recibir importantes nombramientos. A fines de esa década, sus propiedades inmuebles eran considerables, según refleja su testamento de 1 de diciembre de $1679^{5}$.

Esta presencia en el mundo comercial no es sino una prolongación de su propio medio profesional. Nunca desdeñó Mena la colaboración y el trabajo de taller, en el que se había formado ${ }^{6}$. Al fin y al cabo el taller de su padre, Alonso de Mena, fue un núcleo de producción artística y de formación de artistas de gran trascendencia en la Alta Andalucía. Y con anterioridad, los Mena constituían un importante taller de impresores en Granada desde mediados del siglo XVI.

Del mismo modo, para dilatar su horizonte profesional se sirvió de agentes y representantes en su tierra natal y, sobre todo, en la Corte. Preciosos datos al respecto nos ofrecen las cartas enviadas por uno de sus representantes en Madrid, don Sebastián de Benedictis ${ }^{7}$. En ellas se advierte el lógico interés por el exacto cumplimiento de los negocios comprometidos, con la fidelidad y diligencia que en una empresa se requiere. De una de ellas entresacamos el siguiente párrafo, altamente ilustrativo: En quanto a los doscientos ducados de mi señora la Marquesa, no se pierde tiempo, lo que siento no cumpla palabra. Soy stado (sic) con el Sr. D. Pedro Meléndez y me dice oy, mañana, y nuncha (sic) veo camino. No lo dejaré de mi mano asta que se cobren dhos doscientos ducados, para que salgamos desas malas cobranzas $(. . .)^{8}$. También le gestionó contratos en la Corte Felipe de Zayas, mientras que su administrador en Granada fue el escribano Pedro de Urrea.

Si Mena se sirvió habitualmente de agentes comerciales, a su vez intervino de intermediario en distintas operaciones con cierta frecuencia, no sólo en encargos

\footnotetext{
5 Ibídem, págs. 303-309. El escultor estaba avecindado en la parroquia del Sagrario.

6 SÁNCHEZ-MESA MARTÍN, D.: "Algunas noticias sobre la obra de Pedro de Mena", Archivo Español de Arte, t. XL, no 159 (1967), págs. 245-262.

7 ORUETA Y DUARTE, R. de: op. cit., pág. 323 y ss.

${ }^{8}$ La data de la carta, remitida desde Madrid, es 18 de septiembre de 1668. Esta diligencia no era tan correspondida por el escultor al juzgar por lo contenido en otra carta, de 2 de diciembre del mismo año: Con mi Señora $D^{a}$. Catalina de Harco stube el sábado y queda muy quejosa de Vm, yo iré y disculparé a Vm para que vea que Vm tiene muchos deseos de servirla (...). Prueba a un tiempo los buenos oficios del agente Benedictis y los abundantes encargos de Mena en la Corte.
} 
de gran envergadura e interesados, como los que presentamos del cabildo de la Catedral de Granada, sino también para amigos y familiares. Bien lo atestigua la carta desde Granada de don Cristóbal Espinosa de los Monteros, primo de la esposa de Mena, de 7 de noviembre de 1668, en que le pide que le compre un par de medias en Málaga por no hallarlas en Granada o la del proveedor malagueño Juan Manuel de Arbués, que se transcribe en el apéndice documental, solicitando varias piezas de tafetán.

Esta faceta llevó a Mena a prestar a la Catedral de Granada otros servicios distintos de los de su oficio. Su situación era inmejorable, como granadino afincado en una importante ciudad portuaria y comercial como Málaga, lo que le permitía acceder con facilidad a la adquisición de determinadas mercancías, como la cera sin labrar, que luego remitir a los capitulares granadinos. La correspondencia nos muestra, de paso, el farragoso sistema monetario de la época y la pluralidad fiscal sobre las mercancías, datos económicos que aquí poco importan pero con los que estuvo familiarizado nuestro escultor, a lo que parece.

Por otro lado, estas operaciones revelan la estrecha relación mantenida por Mena con el cabildo de la Catedral granadina. Se trata de transacciones directamente encargadas por el Deán o por algún canónigo. En una ocasión, incluso, la cera que se remite constituye una donación personal del Deán de Granada a un convento de monjas, con el grado de intimidad que tal operación requería. No extraña, en cualquier caso, cuando en ese momento Mena se encontraba realizando una obra de considerable relevancia, no sólo artística, sino también simbólica y, desde luego, económica, como fueron las estatuas orantes de los Reyes Católicos para la capilla mayor de esta Catedral, contratadas en tres mil ducados el 10 de agosto de $1675^{9}$. Quizás su presencia en Granada en enero de 1677 tuviera relación con el citado encargo ${ }^{10}$.

Con respecto a estas imágenes, ya en otra parte nos extrañábamos de que un encargo de tanta trascendencia, patrocinado conjuntamente por la Ciudad y por la Catedral de Granada, no recayese en todo un Escultor del Rey como lo era José de Mora, plenamente consagrado y afamado ya en su arte ${ }^{11}$. Con toda probabilidad se encontraba ausente en la Corte, lo que obligó a recurrir al otro gran escultor granadino del momento, aunque afincado en Málaga, Pedro de Mena. Además, conocemos ahora la estrecha relación de Mena con el cabildo granadino y el aval que desde luego supondría su discipulaje de Alonso Cano, con cuyos bustos de Adán y Eva se emparejarían estas figuras orantes. El círculo de relaciones lo cierra el pintor Pedro Atanasio Bocanegra, maestro de pintura de la misma Catedral (nombramiento

\footnotetext{
${ }^{9}$ LLORDÉN, A.: Escultores y entalladores malagueños. Ávila, 1960, pág. 133. Nótese que la primera de las cartas que publicamos se fecha en julio del mismo año.

${ }^{10}$ Entre 1675 y 1677 fecha Orueta la ejecución de estas imágenes, siguiendo a Gómez-Moreno (ORUETA Y DUARTE, R. de: op. cit., pág. 81).

11 LÓPEZ-GUADALUPE MUÑOZ, J.J.: op. cit., págs. 71-72.
} 


\section{Juan Jesús López-Guadalupe Muñoz}

obtenido en 1674 en dura competencia con Juan de Sevilla y con división de opiniones de los capitulares) quien al parecer medió en el asunto y a quien se encomendó la policromía de las mismas ${ }^{12}$.

Por lo que sabemos, la mediación de Bocanegra también le hubiera podido servir a Mora para hacerse con el encargo. Ambos, Mora y Bocanegra, habían contratado en 1671 el retablo de la capilla de San Pedro Pascual de la Catedral de Jaén ${ }^{13}$ y posteriormente, Bocanegra se hospedó en Madrid en la casa del Marqués de Mancera, para el que trabajó Mora ${ }^{14}$. Sin duda, la ausencia de Granada del escultor bastetano y la previsión lejana de un posible retorno por un lado, y el prestigio y buenas relaciones de Mena por otro, acabaron por inclinar la decisión a favor del último, el cual, desde luego, no defraudó en absoluto con su trabajo a sus mecenas. Quizás a ello alude la carta recibida por Mena en Granada a principios del año 1677 , en la que su agente en Málaga se alegra de su feliz llegada a la ciudad de los Cármenes y de que (h)aya cumplido con su obligación a gusto de esos Sres. ${ }^{15}$.

Por todo ello, con toda justicia Palomino pudo afirmar de Mena que fue hombre de la primera estimación, tanto en su arte como en su consideración personal, y de amplias habilidades, a lo que se ve. Su propio carácter, en todo distinto al del otro gran escultor granadino del momento, José de Mora, le llevó a diversificar sus actividades y a dilatar su horizonte profesional, tejiendo una auténtica red de contactos y agentes, que le consiguieron encargos por buena parte de la geografía peninsular. A ello se añadía la alta estimación de su arte (el precio de sus obras era más alto que el de la mayoría de los escultores de su época) y la conciencia de la dignidad profesional del artista, que le condujo a aspirar a un estatus social más elevado, lo que en esta época no podía traducirse más que en una posición económica más que desahogada y en nombramientos de relevancia, como los de Maestro Mayor de Escultura de la Catedral de Toledo $(1663)^{16}$, familiar del Santo Oficio de Granada

\footnotetext{
12 LLORDEN, A.: op. cit., pág. 133; ANDERSON, J.A.: Pedro de Mena, spanish sculptor (1628-1688). University of Michigan , 1970, pág. 104; OROZCO DÍAZ, E.: Pedro Atanasio Bocanegra. Granada,
Universidad, 1937, pág. 31. 13 ULIERTE VÁZQUEZ, L. de: El retablo en Jaén (1500-1800). Jaén, Ayuntamiento, 1986, págs. 309-
310.

14 LÓPEZ-GUADALUPE MUÑOZ, J.J.: op. cit., pág. 84.

15 Siguiendo a Orueta, la amistosa relación con el cabildo granadino debió perdurar en el tiempo, y al poco encontramos a José de Mena y Medrano, hijo del escultor y nacido en Málaga en 1668, como canónigo de la Catedral de Granada, además de ser poeta y anticuario ( ORUETA Y DUARTE, R. de: op. cit., págs.
$62-63$ ).

16 Ibídem, pág. 77 ofrece las únicas noticias al respecto. A título de curiosidad, se puede observar cómo las biografías de los principales artistas del Barroco granadino, Cano, Mena y Mora æcon la facultad de la escultura en comúnæ, se entrecruzan o presentan evidentes y frecuentes paralelismos. Veinte años antes de conseguir Mena el título de escultor de la Catedral de Toledo, fracasó su maestro Cano a la hora de conseguir el cargo de Maestro Mayor de esa Catedral en concurrida oposición celebrada en el verano de 1643, obteniendo poco después un nuevo revés en su pretensión de acceder al mismo título en el Alcázar de Toledo ( PÉREZ SEDANO, F.: Datos documentales inéditos para la Historia del Arte Español. I. Notas del Archivo de la Catedral de Toledo. Madrid, 1914, págs. 91-92 y 120-121;MARTín GONZÁLEZ, J.J.: "Arte y artistas del siglo XVII en la Corte", Archivo Español de Arte, 122 (1958), págs. 125-142). En la citada oposición concursó un tal Juan de la Peña, quizás pariente (?) del arquitecto Gaspar de la Peña que
} 
(1678) o Teniente de Alcaide del Castillo y Fortaleza de Gibralfaro en Málaga (1679), frustrándose su pretensión del título de Escultor del Rey ad honorem (1679), precisamente por gozarlo Mora ${ }^{17}$.

Así se redondean los perfiles de la personalidad de este escultor granadino. Parece claro que fue hábil comerciante, inteligente político y, por supuesto, excelente artista. Lo corroboran los documentos y la trascendencia de su fama a lo largo de los siglos. Sus obras nos devuelven con fuerza el carácter de este polifacético escultor, cuya intimidad y cotidiana existencia se va desvelando a fuerza de estos pequeños hallazgos documentales, que desde luego también matizan su trayectoria profesional.

\section{APÉNDICE DOCUMENTAL}

\section{Documento 1}

Carta de Pedro de Mena remitiendo a Granada un pedido de cera de la Catedral y abono de su importe.

Málaga. 1675, Julio, 16.

Archivo de la Catedral de Granada, Fábrica, legajo 166.

Remito a VS con Juan Pérez, cosario de esta ciudad, a esa, que para junto a las Tablas, un saco o talega (con) un quintal de cera amarilla, más lleba otro quintal i quatro libras de cera blanca en dos marcas i un pan (sic) menor, que ésta se (h)a sacado a once menos quartillo, me holgaré que sea al gusto de VS, la amarilla va con una libra i media más i más libra i quatro onças de tara del saco, lleba su despacho i portes que allá se (h)a de pagar el saco en que ba la amarilla, lo di a el vendedor $i$ se le (h) a de entregar al cosario que ( $h$ a a de traerle un poco de lino = de tal forma que el gasto importa dos mil y cinquenta i cinco reales que VS mandará luego entregar a Bartolomé de Osegura (sic) Mendoça, mi amigo, i suplico a VS se los mande llebar porque está a(h)ora mui ocupado i que los abone a mi

trabaja en la Catedral de Córdoba hasta 1664 y en la de Granada hasta 1666, año en que recibe el título de Maestro Mayor del Palacio del Buen Retiro de Madrid (Archivo de la Catedral de Granada, Actas Capitulares, t. 16, fols. 44 y 208). Este Gaspar de la Peña conoció a José de Mora en Granada y lo avaló en 1672 en su expediente de nombramiento como Escultor del Rey (Archivo General del Palacio Real, Sección de Personal, Caja 706, expediente 1). El puesto sería pretendido también por Pedro de Mena en 1679, cerrándose así el círculo de cruces y paralelismos, no siempre casuales, entre estos artistas. 17 De todo ello se da cuenta en J. L. ROMERO TORRES, "El artista, el cliente y la obra de arte", en Pedro de Mena. III Centenario de su muerte. 1688-1988. Málaga, 1989, págs. 97-114. Compárese con la situación de la época que describe MARTíN GONZÁLEZ, J.J.: El artista en la sociedad española del siglo XVII. Madrid, Cátedra, 1984 


\section{Juan Jesús López-Guadalupe Muñoz}

cuenta. VS me tiene a su ovediencia, que es quanto se ofrece. Nuestro Señor guarde a VS muchos años como deseo. Málaga, I6 de Julio de 1675.

Señor mío

Besa la mano de VS su más servidor

Pedro de Mena i Medrano (rúbrica)

Señor Deán de Granada

\section{(Al margen)}

Recebi de mano del Licenciado D. Diego Garcilópez dos mil y zinquenta $i$ zinco reales que son los contenidos en esta carta que dejo abonados en cuenta de Pedro de Mena y Medrano. Granada y Julio 24 de 1675.

Bartolomé de Osegura (?) Mendoza (rúbrica)

\section{(Al final)}

Mande Vm Señor D. Diego Garcilópez, mayordomo de la hazienda de la fábrica de esta Santa Iglesia pagar a sí mismo y para sí dos mil ciento y veinte y cinco reales que (h) a de (h)aver por los mismos que (h)a pagado de mi orden, los novecientos y veinte i zinco reales del precio de un quintal de cera amarilla por labrar a razón de nueve reales y quartillo la libra $=y$ los un mil ciento y diez $y$ ocho reales del precio de un quintal y quatro libras de cera blanca por labrar a diez reales y tres quartillos la libra $=$ y los doze reales del lienzo en que se trujo en enfardada dha cera desde la ciudad de Málaga a esta ciudad = la qual se trujo para labrarla para el gasto de esta Santa Iglesia como pareze por esta carta que con esta libranza se pagaron, en Granada a quatro de septiembre de mil y seiscientos y setenta y cinco

Dr. Ahumada (rúbrica). 


\section{Documento 2}

Carta de Pedro de Mena remitiendo a Granada un pedido de cera de la Catedral y recibos de su importe.

Málaga. 1675, Diciembre, 11.

Archivo de la Catedral de Granada, Fábrica, legajo 166.

Señor mío

Remito con Juan Pérez, cosario de esta ciudad, a esa las tres cargas de cera que Vm (h)ame mandado, género mui de satisfacción, (h)an pesado 9 quintales y medio, y más libras a raçón de a 9 reales y medio (h)a importado 366 reales de a ocho i más 13 reales de vellón pagados a 25 reales, siendo mexicanos o sevillanos, $i$ entra en esto el enfardelado (sic), 12 varas de bramante i otros gastillos en que incluyen 4 pesos, porque la cera por sí importa 362 pesos i los 13 reales de vellón, pareçe (h)a de parar esta cera a las monjas que Vm gusta dar. Si se ofreciere otra cosa en serbiçio de Vm me lo podrá mandar, cuia vida nuestro Señor guarde muchos años como deseo. Málaga, 11 de diciembre de 1675.

Besa la mano de Vm su más servidor

Pedro de Mena y Medrano (rúbrica)

Señor Dr. D. Miguel Muñoz de Ahumada

(Recibo cosido)

Digo yo, Juan Pérez, cosario y vecino de la ciudad de Málaga, que reciví del señor Don Diego Garcilópez, Mayordomo de la Fábrica mayor desta ciudad ducientos y trece reales que (h)a importado los portes de treinta y seis arrobas de cera y despachos de contrabando, alcabala y quatro por ciento y por ser así y no saber firmar le rogué a un testigo lo firmase, que lo fueron Diego de Espinosa y Antonio Cid Araujo, vecinos desta ciudad de Granada, en ella en veinte y uno de diciembre de mil y seiscientos y sesenta y cinco años.

Son 213 reales de vellón

Antonio Cid Araujo (rúbrica)

(Recibo cosido)

Recivi del señor licenciado don Salbador Gómez de Ribas, thesorero vecino y (ilegible) del Santo Oficio de la ciudad de Granada por mano de el señor licenciado Don Francisco de Alvarado, comisario de dho Santo Oficio, trescientos y sesenta y seis reales de a ocho plata mejicana, a razón cada uno de veinte y cinco reales de vellón. Montan nueve mil ciento y cinquenta reales vellón de que le doy carta de pago y lo firmé en la ziudad de Málaga en siete de henero de mil seiscientos setenta y seis años.

Son 366 a 25 reales de vellón

9150 reales

Pedro de Mena y Medrano (rúbrica). 


\section{Juan Jesús López-Guadalupe Muñoz}

\section{Documento 3}

Carta de Pedro de Mena remitiendo a Granada una carga de cera para la Catedral, letra de pago otorgada por Mena y abono de su importe.

Málaga. 1676, Abril, 20.

Archivo de la Catedral de Granada, Fábrica, legajo 166.

Señor mío

Con Juan Pérez, cosario de esta ciudad, a esa remito doçe arrovas i once libras de cera blanca a poder de Vm de orden del señor Deán de esa Santa Iglesia, $i$ su valor a diez reales y cuarto (h)a importado 3187 reales y tres cuartos, salvo error, va pagado el porte i asimismo (h)e pagado el despacho, Vm me dará aviso de su recibo i asimismo de (h)aver llegado una letra de 3500 reales que di a $D$. Joseph de Acedo a favor de D. Gabriel Ruiz, veinte y quatro de esa ciudad, i la resta queda abonada en mi libro para que esté a disposición del señor Deán i de Vm, que es quanto se ofrece, quedando siempre al servicio de Vm, cuia vida guarde nuestro Señor muchos años. Málaga i abril 20 de 1676.

Besa la mano de Vm su más servidor

Pedro de Mena y Medrano (rúbrica)

Señor D. Diego Garcilópez

(Recibo cosido)

Jesús, María, Joseph. Málaga, 18 de abril de 1676 años.

Son 3500 reales de vellón.

A quatro días vista mandará Vm pagar a la voluntad de el señor D. Gabriel Ruiz, veinte y quatro de la ciudad de Granada, tres mil i quinientos reales de vellón que valen ciento i diez i nueve mil maravedís por la valor recevida del señor D. Joseph de Acedo, que son los mismos que (h)a importado la cera que tengo remitida para la Santa Iglesia de esa ciudad, como lo aviso al Señor Deán por el correo. Cristo con todos.

Pedro de Mena y Medrano (rúbrica)

(Recibo cosido)

Mande Vm señor D. Diego Garcilópez, mayordomo de la hazienda de la Fábrica de esta Santa Iglesia pagar a sí mismo y para sí tres mil trecientos (sic) 
y siete reales y tres quartillos que ( $h)$ a de aver por los mismos que $(h)$ a de pagar y $(h) a$ pagado en esta manera $=$ los tres mil ciento y ochenta y siete reales y tres quartillos a Pedro de Mena Medrano o a quien el susodho huviere ordenado, del precio de doze arrobas y onze libras de cera blanca a diez reales y quartillo la libra, que el susodho compró en la ciudad de Málaga para labrarla en esta Santa Iglesia para su gasto = $y$ los veinte y seis reales y medio de gastos de la saca de dha cera y traerla desde la aduana y los sesenta y dos reales y medio que pagó del porte della, desde Málaga a esta ciudad $=y$ los treinta y un reales restantes, que pagó a Julián Descalzo por tres libras y catorce onzas de velillas de cera, que entregó, toda la qual dha cera se (h)a entregado al Lizenciado Don Fabián de Robles, administrador de la utensilia (sic) de esta dha Santa Iglesia = y su prezio y costa pareze por la memoria que va con esta libranza en carta del dho Pedro de Mena, que con esta libranza y su recibo serán bien dados y se pagarán en Granada a veinte y ocho de Abril de mil y seiscientos y setenta $y$ seis años.

Dr. Ahumada (rúbrica).

\section{Documento 4}

Carta remitida a Pedro de Mena a Granada en que se da cuenta de un envío de cera para la Catedral y abono de su importe.

Málaga. 1677, Enero, 6.

Archivo de la Catedral de Granada, Fábrica, legajo 166.

Señor mío

Me (h) a alegrado mucho que Vm (h)aya llegado a esa ciudad con salud i que (h)aya cumplido con su obligación a gusto de esos Sres., de la sera que tengo en casa le remito a Vm ocho arrobas y nueve libras, que tiene de costa a razón de diez reales, 2090 reales y 27 reales de lienzo i papel sellado y firmas del Governador, y que lo demás que toca a despachos me hizieron grasia = Aunque Vm se halle mui ocupado, me (h)a de hazer favor de remitirme una pieza de tafetán doble blanco y otra piesa de tafetán doble rosado con cochinilla, y si no (h)ubiere las piesas cavales, lo que (h)ubiere me lo remitirá Vm, y el correo remita la satisfacción, esto pide brevedad y así no escuse Vm hazerme este favor, atendiendo que me tiene Vm mui a su servisio y reconosido, el portador de la sera es Miguel Garzía. Guarde Dios a Vm. Málaga, Henero 6 de 1677 años. 


\section{Juan Jesús López-Guadalupe Muñoz}

Besa la mano de Vm ŝu mayor servidor y amigo

Joan Manuel de Arbués (rúbrica)

Sr. Pedro de Mena Medrano

\section{(Al dorso)}

Mande Vm Sr. D Diego Garzilópez, Maiordomo de la hazienda de la fábrica Mayor desta Santa Iglesia pagar a sí mismo y para sí dos mil ciento y setenta y nueve reales y medio que $(h)$ a de aver, los dos mil ciento y diez y siete reales que pagó a Pedro de Mena Medrano, los dos mil y noventa reales dellos del precio de ducientas y nueve libras de zera blanca en marcas a precio de diez reales la libra $y$ los veinte y siete reales de lienzo en que bino envuelta y papel y el despacho de dicha zera que se (h)a traido para labrarla para el gasto desta dha Santa Iglesia = y los sesenta y dos reales y medio restantes del porte que pagó al harriero que trujo dha cera desde la Ciudad de Málaga hasta esta ciudad y derechos y quatro por ciento que pagó, que con esta libranza y su recibo serán bien dados, fha en Granada a catorce de henero de mil y seiscientos y setenta y siete años

Dr. Ahumada (rúbrica). 